\title{
MULTIELEMENTAR ADSORPTION OF METAL IONS USING TURURI FIBERS: EXPERIMENTS, MATHEMATICAL MODELING AND NUMERICAL SIMULATION
}

\author{
D.Q. MELO ${ }^{1}$, C. B. VIDAL ${ }^{2}$, G.S.C. RAULINO ${ }^{2}$, A.D. LUZ SANTOS ${ }^{3}$, C. LUZ $^{3}$ e R.F \\ NASCIMENTO ${ }^{2}$ \\ ${ }^{1}$ Universidade Ferderal do Ceará, Departamento de Química Analítica e Físico-Química \\ ${ }^{2}$ Universidade Federal do Ceará, Departamento de Engenharia Hidráulica e Ambiental \\ ${ }^{3}$ Universidade Federal da Fronteira Sul, Departamento de Engenharia Ambiental \\ E-mail para contato: diegodqm@gmail.com
}

\begin{abstract}
A numerical and experimental study of the multielementar adsorption of $\mathrm{Cd}^{2+}, \mathrm{Cu}^{2+}, \mathrm{Ni}^{2+}$ and $\mathrm{Pb}^{2+}$ ions in a batch reactor and fixed-bed column was carried out in aqueous solution at $28{ }^{\circ} \mathrm{C}$, using tururi fibers as the adsorbent. The kinetics and thermodynamic equilibrium parameters were obtained for all metal ions. The adsorption kinetics was fitted to the homogeneous diffusion model, giving good linear correlation coefficients. Furthermore, a mathematical model was built to describe the mass transfer kinetics in a fixed-bed column. The effects of constant adsorption equilibrium, external mass transfer and intra-particle diffusion resistance on breakthrough curves were studied. The equations which describe the phenomenology were discretized using the Finite Volumes Method with the WUDS and CDS formulations. The results for the breakthrough curves obtained through simulation showed good agreement when compared with the experimental data.
\end{abstract}

\section{INTRODUCTION}

Toxic metals are continuously used in industrial activities, contaminating aquatic environments and may be present in toxic concentrations in the air due to the incineration of municipal and industrial wastes (Baird, 2002). The non-degradability, toxicity, carcinogenic or mutagenic effects of these pollutants has received special attention, even in very low concentrations. The removal and recovery of toxic metals are very important with regard to economic matters and especially environmental. Consequently, the implementation of removal technologies for the treatment of effluents from various industries (mining, textile, painting, electroplating, pesticide-producing, petrochemical) has become a matter of urgency, since in many cases the effluents are discarded into water bodies with no suitable treatment (Melo et al., 2013).

However, the majorities of methods have limitations such as high operating costs, incomplete removal of metal ions; in addition to generating secondary pollution, such as, sludge by precipitation with sodium hydroxide. Adsorption using lignocellulose-derived materials have been studied as adsorbents including cellulosic substrates (Hubbe et al., 2011), sugar cane bagasse (Sanchez and 


\section{9 a 22 de outubro de 2014 \\ Florianópolis/SC}

Espósito, 2011), cashew bagasse (Moreira et al., 2009), coconut shell (Neto et al., 2012). A major advantage of using natural fibers as adsorbents is the ready availability of renewable sources in nature, the low costs, the biodegradability, as well as the excellent mechanical properties.

Natural fibers of vegetable origin are complex composite materials, consisting primarily of cellulosic microfibrils in an amorphous matrix of lignin and hemicellulose. Originally from the Amazon estuary, the palm of ubuçu (Manicaria saccifera) has carries fruits protected by a fibrous sheat called 'tururi'. Despite the fact that this fiber has economic importance in a number of commercial sectors, there are no studies known on its physical and chemical properties for potential use in adsorption processes. The present work focuses on adsorption and removal of metal ions $\mathrm{Pb} 2+$, $\mathrm{Cu}^{2+}, \mathrm{Ni}^{2+}$ and $\mathrm{Cd}^{2+}$ from aqueous solutions using tururi fiber as an adsorbent.

In this context, the aim of this research is to study the fixed-bed adsorption, equilibrium and kinetics of the metal ions in aqueous solution, batch reactor at $28+/-2{ }^{\circ} \mathrm{C}$ using tururi fibers as adsorbent and thus use the parameters obtained for simulation of the breakthrough curves of metal ions in fixed bed column. The mathematical model used is a cluster model of pore diffusion which considers the internal and external resistances to mass transfer to the adsorbent particles. The finite volume method was used in the Discretization of the equations with the interpolation function Weight Upstream Differencing Scheme (WUDS) along the column and the Central Difference Scheme (CDS) along the particle and the algorithm was implemented in the FORTRAN programming language.

\section{MATERIALS AND METHODS}

Analytical-grade chemicals and ultrapure water (Millipore Direct Q3 Water Purification System) were used to prepare the solutions. Multi-element stock solutions of $\mathrm{Cd}^{2+}, \mathrm{Cu}^{2+}, \mathrm{Ni}^{2+}$, and $\mathrm{Pb}^{2+}\left(500 \mathrm{mg} . \mathrm{L}^{-1}\right)$ were prepared with $\mathrm{Cd}\left(\mathrm{NO}_{3}\right)_{2} \cdot 4 \mathrm{H}_{2} \mathrm{O}, \mathrm{Cu}(\mathrm{NO} 3) 2.3 \mathrm{H} 2 \mathrm{O}, \mathrm{Ni}\left(\mathrm{NO}_{3}\right)_{2} \cdot 6 \mathrm{H}_{2} \mathrm{O}$, and $\mathrm{Pb}$ (NO3)2 (Merck, São Paulo, Brazil), respectively. The acetate buffer was prepared with sodium acetate and glacial acetic acid. $\mathrm{NaOH}\left(0.10 \mathrm{~mol} . \mathrm{L}^{-1}\right)$ and $\mathrm{HCl}\left(0.10 \mathrm{~mol} . \mathrm{L}^{-1}\right)$ solutions were used for $\mathrm{pH}$ adjustments. Tururi fibers were supplied by Embrapa Tropical Agro-industry, CE, Brazil (EMBRAPA/CE).

Erlenmeyers $(50.0 \mathrm{~mL})$ and an orbital shaker device (Marconi, Piracicaba, SP, Brazil) operating at $200 \mathrm{rpm}$ and at $28 \pm 2{ }^{\circ} \mathrm{C}$ were used in the isotherms experiments. The adsorbent $(50.0 \mathrm{mg})$ and the aqueous solutions $(25.0 \mathrm{~mL})$ containing the adsorbate were added to each flask. The experiments were performed in duplicate. The equilibrium adsorption capacities of the adsorbent were calculated using Equation 1:

$$
q_{e}=\frac{V\left(C_{i n}-C_{e}\right)}{M}
$$

where: qe is the equilibrium adsorption capacity (mg of metal/g adsorbent), Co is the initial concentration of the metal ion (mg.L ${ }^{-1}$ ), Ce is the equilibrium concentration of metal ion (mg.L $\mathrm{L}^{-1}$ ), V is the volume of the solution $(\mathrm{L})$, and $\mathrm{W}$ is the mass of adsorbent $(\mathrm{g})$. Control experiments were carried out in the absence of adsorbent to check for any adsorption on the walls of the flasks. The multielementar isotherm model used in this work was the Langmuir isotherm. 
Adsorption kinetics allows to evaluate the extent of removal of metal ions as well as to identify the prevailing mechanisms involved in the adsorption process. A multi-element solution (100.0 mg. $\left.\mathrm{L}^{-1}\right)$ was continuously shaken $(200 \mathrm{rpm})$ at $\mathrm{pH}$ 5.5. Aliquots of the supernatant were collected at regular time intervals, up to $60 \mathrm{~min}$. Adsorption capacities were calculated by the differences between the initial and the final concentrations at any given time. The experimental data of the adsorption kinetics of the multielementar metal ions were adjusted by the homogenous diffusion model in particle according to Equation 2 (Ruthveen, 1984).

$$
\frac{\partial q}{\partial t}=\frac{1}{r^{2}} \frac{\partial}{\partial r}\left\{r^{2} D_{e f} \frac{\partial q}{\partial r}\right\}
$$

with the following initial (IC) and boundary conditions (BC):

$$
q(r, 0)=q_{0} ; \quad q(r, t)=q_{0} ;\left.\frac{\partial q}{\partial r}\right|_{r=0}=0
$$

where: $\mathrm{r}$ is the position in the radius from the center of the particle considered to be spherical, $\mathrm{t}$ is the time, and $\mathrm{D}_{\mathrm{ef}}$ is the effective diffusivity coefficient.

An adsorption column (9.5 $\mathrm{cm}$ height and $1.0 \mathrm{~cm}$ diameter) was prepared with the adsorbent $(2$ g). About $160 \mathrm{~mL}$ of the multi-element solution $\left(300 \mathrm{mg} \cdot \mathrm{L}^{-1}\right)$ was passed through the column at a flow rate of $2.0 \mathrm{~mL} \mathrm{~min}^{-1}$ and samples of $4 \mathrm{~mL}$ each were collected at the outlet of the column prior to analyses.

The mathematical model is a grouped model of diffusion in the pores, which considers the mass transfer resistance inside and outside the particle adsorbent. Mathematical modeling of this process involves the equations of chemical species conservation in the liquid and solid phases, which describe the variation of the solute concentration inside the column and the particle with respect to time and position, as well as initial boundary conditions. The surface diffusion coefficient (Ds) was assumed to increase exponentially with surface coverage according to Equation 3.

$$
D s(q)=D_{e f} \exp \left[k\left(\frac{q}{q_{s a t}}\right)\right]
$$

where: $D_{\text {ef }}$ is the diffusion coefficient at $q=0, k$ is a parameter of Equation 3 , $q$ is the concentration of the solute in the solid phase, and $\mathrm{q}_{\text {sat }}$ is the saturation concentration of the solute at the surface. Equation 3 was incorporated into the adsorption model to take into account the variation in the surface diffusion coefficient Ds as a function of time and position within the particles (Chatzopoulos and Varma, 1995). Setting k = 0 in Equation 3 also allowed for the use of a constant (concentration independent) Ds.

In this case, the concentration of the solute in the liquid phase, $\mathrm{C}$, varies with the axial position $\mathrm{z}$ and the time $\mathrm{t}$, while the concentration in the solid phase $\mathrm{q}$ is a function of the radial position $\mathrm{r}$ inside the particle. Assuming an isothermal process because of the high heat capacity of water; 
spherical adsorbent particles and fast adsorption kinetics, the solute mass balance in the solid phase is given by Equation 4.

$$
\frac{\partial q}{\partial t}=\frac{D_{e f}}{r^{2}} \frac{\partial}{\partial r}\left\{r^{2} \exp \left[k \frac{q}{q_{s a t}}\right] \frac{\partial q}{\partial r}\right\}
$$

With the following initial (IC) and boundary conditions (BC):

$$
\begin{aligned}
& \text { IC: } \quad t=0, \quad 0 \leq \mathrm{r} \leq \mathrm{R}, \quad 0 \leq \mathrm{Z} \leq \mathrm{L}, \quad \mathrm{q}_{\mathrm{i}}=0 \\
& \text { BC1: } \quad t>0, \quad 0 \leq z \leq L,\left.\frac{\partial q}{\partial r}\right|_{r=0} \quad(4 \mathrm{~b}) \\
& \text { BC2: } \quad t>0, \quad 0 \leq z \leq L,\left.\quad D_{\mathrm{ef}} \rho_{s} \exp \left[k\left(\frac{q}{q_{s a t}}\right)\right] \frac{\partial q}{\partial r}\right|_{r=R}=k_{f}\left(C-C_{e}\right)
\end{aligned}
$$

where: $\rho_{s}$ is the solid density, $\mathrm{k}_{\mathrm{f}}$ is the external mass transfer coefficient and Ce is the solute concentration in the liquid phase at the solid-liquid interface. The initial condition used to describe the model for solid phase requires, along the bed at time zero, the concentration in the solid phase is equal to zero for adsorption. The boundary conditions employed in the model are symmetry and equality of flows.

In the absence of axial solute dispersion in the bed, the solute mass balance in the fluid phase along with the relevant IC and BC is expressed by Equation 5, where in (5a) and (5b) are the initial condition and the boundary, respectively, for this Equation.

$$
\begin{aligned}
& \frac{\partial C}{\partial t}=-\frac{v_{s}}{\varepsilon} \frac{\partial C}{\partial z}-\frac{3}{R} \frac{(1-\varepsilon)}{\varepsilon} k_{f}\left(C-C_{e}\right) \\
& I C: t=0 \quad 0 \leq \mathrm{z} \leq \mathrm{L} \quad \mathrm{C}=0 \\
& B C: t>0 \quad z=0, \quad C=C_{\text {in }}(t)
\end{aligned}
$$

where: $v_{S}$ is the superficial velocity of the liquid in the bed, $\varepsilon$ is the bed porosity, and $\mathrm{R}$ is the radius of the adsorbent particle. The time-varying $\mathrm{BC}$ at the bed inlet in Equation $6 \mathrm{~b}$ was employed primarily to lend greater flexibility to the model so that it can handle experiments under variable influent-concentration conditions. However, this feature of the model also allowed for the successful description of discontinuities in the experimental breakthrough curves caused by small variations of the influent concentration $\mathrm{C}_{\mathrm{in}}$, with time due to the batch wise production of feed solution. Because of the assumption of fast intrinsic adsorption kinetics, the solid-phase and liquid-phase solute concentrations at the solid-liquid interface can be related through the equilibrium isotherm, expressed by Equation 2.

The finite volume method was used to discretize the conservation equations. The choice is due to the fact that it ensures the conservation of the quantities involved, both at the elementary level and globally. In this work, we used the explicit formulation and one-dimensional structured mesh for 
storing discrete points. In the computational mesh, we used a co-located arrangement of variables, where all variables are stored in the center of the control volumes. For the evaluation of the variables and their derivatives on the faces of the control volumes, the Weight Upstream Differencing Scheme (WUDS) along the column and the Central Difference Scheme (CDS) throughout the particle were applied.

\section{RESULTS AND DISCUSSION}

The equations that describe the adsorption of metals $\left(\mathrm{Cu}^{2+}, \mathrm{Cd}^{2+}, \mathrm{Ni}^{2+}, \mathrm{Pb}^{2+}\right)$ in the mixture using a fixed bed column were solved aiming to validate the proposed mathematical model and numerical methodology developed. The results obtained by simulation are compared with the experimental data. The input parameters of the model to determine the concentration profiles of ions metal in the mixture are shown in Table 1.

Table 1 - Parameters used to obtain the multicomponent breakthrough curves of metal ions on tururi.

\begin{tabular}{|c|c|c|c|c|}
\hline Parameters & $\mathbf{C u}^{2+}$ & $\mathbf{C d}^{2+}$ & $\mathbf{N i}^{2+}$ & $\mathbf{P b}^{2+}$ \\
\hline $\mathrm{C}_{\text {in }}(\mathrm{mg} / \mathrm{L})$ & 276.72 & 299.532 & 306.525 & 303.70 \\
\hline$\varepsilon_{L}(\mathrm{adim})$ & 0.7333 & 0.7333 & 0.7333 & 0.7333 \\
\hline$D_{m}\left(\mathrm{~cm}^{2} / \mathrm{s}\right)$ & $7.13 \times 10^{-6}$ & $7.17 \times 10^{-6}$ & $6.79 \times 10^{-6}$ & $9.25 \times 10^{-6}$ \\
\hline$D_{e f f}\left(\mathrm{~cm}^{2} / \mathrm{s}\right)$ & $8.9 \times 10^{-3}$ & $1.634 \times 10^{-3}$ & $1.632 \times 10^{-3}$ & $7.743 \times 10^{-3}$ \\
\hline$\rho_{s}(\mathrm{~g} / \mathrm{L})$ & 635.75 & 635.75 & 635.75 & 635.75 \\
\hline$d_{p}(\mathrm{~cm})$ & 0.0595 & 0.0595 & 0.0595 & 0.0595 \\
\hline$D_{c}(\mathrm{~cm})$ & 1.0 & 1.0 & 1.0 & 1.0 \\
\hline$Q(\mathrm{~mL} / \mathrm{min})$ & 4.0 & 4.0 & 4.0 & 4.0 \\
\hline$L(\mathrm{~cm})$ & 9.5 & 9.5 & 9.5 & 9.5 \\
\hline$b(\mathrm{~L} / \mathrm{g})$ & 0.004702 & 0.005882 & 0.01525 & 0.001903 \\
\hline$q_{\max }(\mathrm{mg} / \mathrm{g})$ & 104.0314 & 126.7545 & 48.8279 & 52.5889 \\
\hline $\mathrm{k}_{\mathrm{f}}$ & $1.76 \times 10^{-3}$ & $1.76 \times 10^{-3}$ & $1.70 \times 10^{-3}$ & $2.09 \times 10^{-3}$ \\
\hline
\end{tabular}

Figure 1 shows the breakthrough curve of metals $\left(\mathrm{C} / \mathrm{C}_{\mathrm{in}}\right)$, using the mathematical model with the parameters shown in Table 1 , where $C_{\text {in }}$ is the mass concentration of metals in the feed, in function of time. The numerical results in Figure 2 presented a deviation in relation to the experimental data for the multielementar breakthrough curves. This deviation can also be explained by the short bed and high flow rate, which mean that the compounds adsorbed at the top of the bed are desorbed with greater facility (Vidal et al, 2014). 


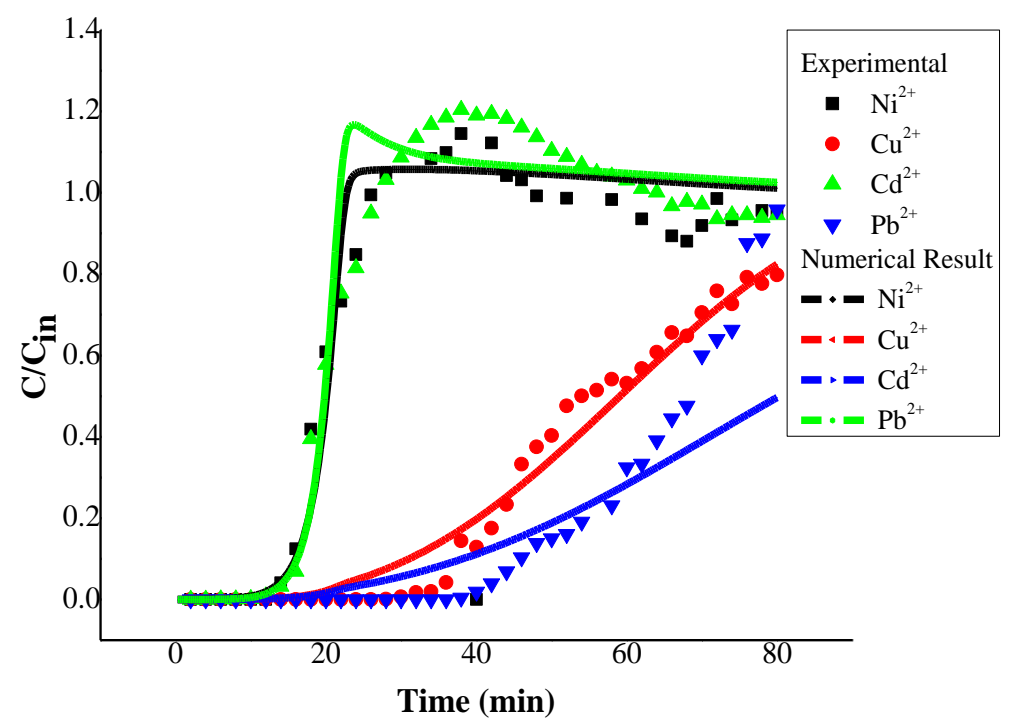

Figure 1 - Experimental and simulated breakthrough curves of metal ions.

According to Sulaymon and Ahamed (2008), a plausible explanation for the deviation in the adimensional concentration of the points on the breakthrough curve, mainly for compounds which are weakly adsorbed, is related to the Biot number. The Biot number is an adimensional number and it represents the relation between the resistance to internal mass transfer by diffusion and the resistance to external mass transfer by convection. In the present work the following Biot numbers were found for the BTX compounds: $\mathrm{Bi}_{\mathrm{Cd}}=10.23 ; \mathrm{Bi}_{\mathrm{Ni}}=9.90 ; \mathrm{Bi}_{\mathrm{Cu}}=9.50$ and $\mathrm{Bi}_{\mathrm{Pb}}=2.56$.

The competitive adsorption rate will decrease as the average Biot number increases for each adsorbate, leading to a lower breakpoint because of the low intraparticle resistance and the reduction in the contact time. The increase in the bed height leads to an increase in the competitive adsorption rate, and the displacement of the weak components will be greater. A lower Biot number was observed for $\mathrm{Pb}$, where a higher intraparticle diffusivity of this metal ions occurs compared with the others. This corroborates the mathematical model and the numerical methodology used, demonstrating that they represent the real adsorption process with good accuracy and allowing other situations to be simulated. According to Cooney (1999) the external mass transfer is totally dominating at $\mathrm{Bi}<0.5$, while the adsorption process is limited by intraparticle diffusion for $\mathrm{Bi}>30$.

With the objective of predicting the operating conditions of an adsorption process, we performed a sensitivity parametric analysis of the operational conditions. The parameters studied include volumetric flow, bed height, and bed porosity. Figure 2 shows the numerical results of the multicomponent breakthrough curves of the metal ions using an initial concentration of $\mathrm{C}_{\mathrm{inCu}}{ }^{2+}=$ 276.720; $\mathrm{C}_{\mathrm{inCd}^{2+}}=299.532 ; \mathrm{C}_{\mathrm{inNi}}{ }^{2+}=276.720 ; \mathrm{C}_{\mathrm{inPb}^{2+}}=299.532$ compared to the real experiments conditions: bed porosity, $\varepsilon_{\mathrm{L}}$, of 0.73 , and a bed height, $\mathrm{L}$, of $9.5 \mathrm{~cm}$ and flow of the system, $\mathrm{Q}=4 \mathrm{~mL}$. $\min ^{-1}$ ). 

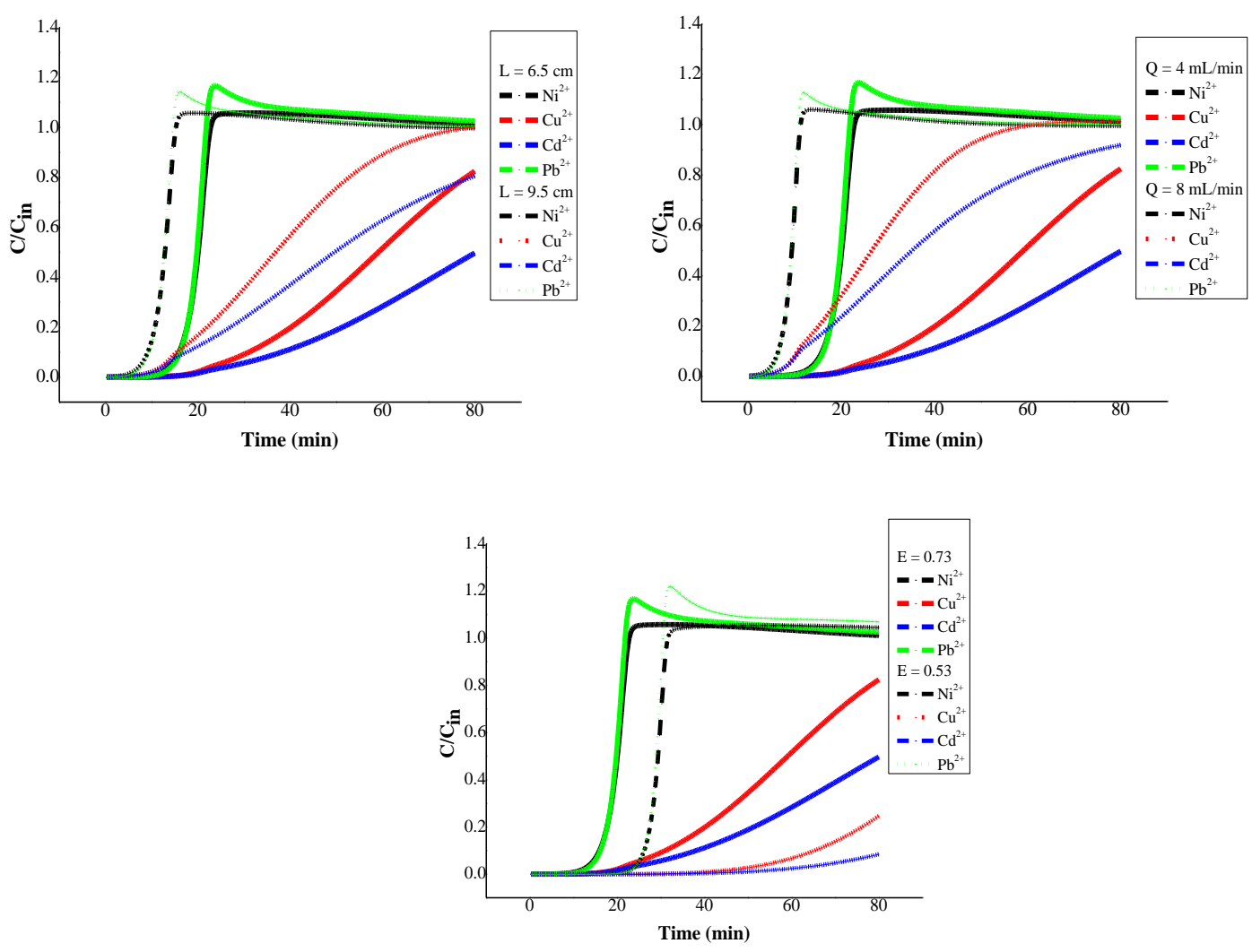

As the flow increases, the breakthrough times of the metal ions compounds decrease as well the adsorption capacity of the tururi fiber for each metal ions. The increase in flow rates implies a reduction in the hydraulic retention time (HRT) of the compounds inside the column. According to Cooney (1999) the HRT is a typical parameter of design and operation for the usage of columns. Long residence times can lead to a decrease in contaminant removal, whereas shorter times do not allow an effective contact for the interaction between the adsorbent and the adsorbate. As the porosity of the bed increases, the void space also increases, thus decreasing the number of active sites inside the column. As a result, the adsorption capacity of the bed is smaller than the breakthrough times.

\section{CONCLUSIONS}

An experimental and numerical study of adsorption of metal ions on tururi in aqueous solution was carried out. The multicomponent Langmuir model was used to describe the equilibrium in the multicomponent system. The kinetics in a batch reactor showed that the multicomponent adsorption equilibrium was reached after $20 \mathrm{~min}$. The numerical results presented a good agreement in relation to experimental data for the multicomponent breakthrough curves. With an increase in the bed height, the breakthrough times of the metal ions increased. As the flow increased, the breakthrough times of the metal ions underwent a decrease. The adsorption process was represented with good accuracy by the mathematical model and the numerical methodology used, allowing other situations to be 
simulated.

\section{REFERENCES}

BAIRD, C. Química Ambiental. Porto Alegre: Editora Bookman, 2002.

COONEY, D. O. Adsorption Design for Wastewater Treatment. Boca Raton: CRC Press, 1999.

HUBBE, M.A.; HASAN, S.H.; DUCOSTE, J.J. Cellulosic substrates for removal of pollutants from aqueous systems: A review. Metals Biores., v.6, p.2161-2287, 2011.

MELO, D. Q.; GOMES, E. C. C.; RAULINO, G. S. C.; LONGHINOTTI, E.; NASCIMENTO, R. F. Adsorption equilibria of $\mathrm{Cu}^{2+}, \mathrm{Zn}^{2+}$, and $\mathrm{Cd}^{2+}$ on EDTA-functionalized silica. J. Chem. Eng. Data., v.58, p.798-806, 2013.

MOREIRA, S. A.; SOUSA, F. W.; OLIVEIRA, A. G.; BRITO, E. S.; NASCIMENTO, R. F. Remoção de metais de solução aquosa usando bagaço de caju. Quim. Nova. v.32, p.1717-1722, 2009.

NETO, V. O. S.; CARVAlHO, T. V.; HONORATO, S. B.; GOMES, C. L.; FREITAS, F. C.; SILVA, M. A. A.; FREIRE, P. T. C.; NASCIMENTO, R. F. Coconut bagasse treated by thioureia/ammonia solution for cadmium removal: kinetics and adsorption equilibrium. Bioresource. v.7, p. 1504-1524, 2012.

RUTHVEN, D. M. Principles of Adsorption and Adsorption Processes. New York: John Wiley \& Sons, 1984.

SANCHEZ, R. A.; ESPÓSITO, B. P. Preparation of sugarcane bagasse modified with the thiophosphoryl function and its capacity for cadmium adsorption. Bioresource, v.6, p. 2448-2459, 2011.

SULAYMON, A. H.; AHMED, K. W. Competitive adsorption of furfural and phenolic compounds onto activated carbon in fixed bed column. Environ. Sci. Technol. v. 42, p. 392-397, 2008.

VIDAL, C.B.; RAULINO,G.S.C.; LUZ, A.D.; LUZ,C. NASCIMENTO, R.F. KEUKELEIRE, D. Experimental and Theoretical Approach to Multicomponent Adsorption of Selected Aromatics on Hydrophobically Modified Zeolite. J. Chem. Eng. Data, v.59, p 282-288. 